\title{
Problems of Chinese Agricultural Industrialization and Solutions
}

\author{
Wang Xufei \\ Yangtze University, Jingzhou, 434023, China
}

Keywords: agricultural industrialization, development problems, solutions

\begin{abstract}
As the foundation of China's economy, agriculture plays a pivotal role in national economic development. With the development of market economy, agricultural industrialization emerges as a natural result of the reform and development of agriculture and rural economy. It is also an important innovation for China's agricultural operating system to better meet the needs of agricultural productivity. This paper introduces the definition and characteristics of agricultural industrialization management and analyzes the theoretical basis of its inception and development. It also analyzes problems in China's agricultural industrialization development, and puts forward corresponding solutions: a multi-pronged model driven by leading enterprises, specialized market and intermediary organizations.
\end{abstract}

\section{Introduction}

Agriculture is the foundation of China's development. When the agriculture develops, China's economy will grow; when farmers see their livelihoods improved, the country will prosper. To bring prosperity to agriculture and then to China, one of the major tasks is to develop the rural economy and increase farmers' income. Furthermore, to truly witness a booming rural economy, the central task is to transform the traditional agricultural production pattern and rural economy development methods. The best answer to secure that success was told by theories and practices from both home and abroad: agricultural industrialization. [1] It is an important method to actively promote the structural adjustment of agricultural industry, continuously improve agricultural competitiveness and steadily increase farmers' income. As a newly-emerged agricultural production and management system in China, agricultural industrialization is the result of accumulative practices of regional agricultural development, reflecting the requirements of advanced agricultural productive forces. [2] Agricultural industrialization is featured by specialization in production, localization, business integration, society-based service and enterprise-based management. Guided by market demands, it integrates the production, processing and sales of agricultural products, effectively improving the international competitiveness of China's agricultural products. In addition, it also provides solution to problems related to rural areas, farmers and agriculture, the optimization of agricultural industrial structure and the transformation from traditional agriculture to modern agriculture.

\section{Definition of Agricultural Industrialization}

In 1995, the Ministry of Agriculture of the People's Republic of China clearly explained agricultural industrialization for the first time in its first agricultural white paper China Agricultural Development Report: Under the market economy, agricultural industrialization integrates pre-production, mid-production and post-production into a complete industrial system. Through this, an integrated management system of planting, breeding and processing, production, supply and marketing, trade, industry and agriculture can be established. By doing that, the added value and comparative benefit of agriculture can be improved, forming an advanced development mechanism characterized by self-accumulation, self-development and virtuous cycle.[3] In practice, it stands out with production specialization, localization, business integration, society-based service and enterprise-based management. [4] The definition of agricultural industrialization in this paper is as follows: based on the premise of maintaining the stability of the household contract responsibility 
system with remuneration linked to output, in pursuit of economic benefits and guided by market demands, agricultural industrialization is committed to production specialization, localization and social-based service in regional agricultural leading industries. [5] By doing that, a comprehensive production and management system will be established, integrating planting, breeding and processing, production, supply and sales, agriculture, industry, trade, science and education.

\section{Problems of Chinese Agricultural Industrialization}

After nearly 30 years of development, China's agricultural industrialization management has made remarkable achievements. It has played an important role in increasing farmers' income and improving agricultural products' competitiveness. Besides, it has also greatly promoted China's agricultural modernization and the development of a new socialist countryside. However, while achieving remarkable achievements, China has also been faced of some problems in the process of agricultural industrialization.

\subsection{Insufficient competitiveness of leading enterprises}

Most of the cooperative organizations in China's agricultural industrialization are voluntary organizations of some SMEs or farmers. Without the support of large-scale leading companies, there is no stability and sustainability brought by these enterprises. Furthermore, most of the leading enterprises in agricultural industrialization are still small companies. Their economic strength is weak, influence is limited and their resilience to market and natural risks is insufficient. At the same time, these small leading companies enjoy no advantages whether in the technological competitiveness of their products or the marketing expertise. Problems of leading enterprises have directly influenced the production and sales chain of agricultural products.

\subsection{Problems of market operational mechanism}

Agricultural industrialization is market-oriented. Although China's rural market system is developing rapidly, there are still some problems. First, the market system needs improvement. In rural areas, the agricultural product market has developed fast. However, owing to various factors such as regional blockade and departmental division, reasonable flow of production factors such as land, labor, capital, and technology cannot be secured. Second, this rural market is not mature. Unreasonable profits distribution between leading enterprises and farmers makes it unable for farmers to benefit from agricultural products transportation, processing and so on. This problem reduces the enthusiasm of farmers and increases risks and uncertainties in agricultural production. Third, related market regulations are not comprehensive. For example, laws and regulations that are complementary to agricultural industrialization have not been introduced. In addition, some existing laws and regulations are not stipulated in a scientific way or not suitable to the market. Besides, supervision and enforcement of certain laws and regulations are not enough.

\subsection{Insufficient support from government to agricultural industrialization}

This problem is revealed in three areas. First, policies and regulations related to agricultural industrialization are not enough. Although some preferential policies have been introduced in recent years, government's supporting policies are still backward and not fully implemented. Second, the municipal and county-level governments have not established a special fund for the development of agricultural industrialization. It is still difficult for enterprises to access financing and secure development. Third, there is a lack of specific supporting policies to farmers' professional economic cooperation organizations. More policies should be introduced to serve as backup and fully implemented, especially those aiming to provide services to farmers' professional economic cooperation organizations in information, technology, training, quality standards \& certifications and marketing. 


\section{Suggestions to develop Chinese Agricultural Industrialization}

To solve the problems of China's agricultural industrialization, this paper will build a multipronged model with the aim of promoting the rapid, healthy and steady development of China's agricultural industrialization. This model asks for improvement in agricultural industrialization model and support to leading enterprises. Funding channels should be expanded to ensure the smooth development of agricultural industrialization. Society-based service system and market system should be improved. Besides, governmental function should also be transformed to be more supportive to this process. At the same time, agricultural industrialization should be developed step by step in accordance with the reality in China.

\subsection{Driven forces of leading enterprises}

To develop leading enterprises as a driven force is the common mode of agricultural industrialization in practice. Through the "enterprise + small farmers" model, influential leading enterprises can take the lead in development and motive farmers. Based on an analysis to local advantages, this mode will integrate farmers' production with the production, processing, and sales of enterprises. Guided by market demands and agreed interest-linking mechanism, an industry chain combing farming, breeding and processing, agriculture, industry and commerce can be established. During this process, a community of shared interests can also be launched. By doing that, related agricultural enterprises, agricultural production bases and regional agricultural economy can be driven to prosper and the comprehensive benefits of agriculture will increase. To ensure leading enterprises can instill momentum to agricultural industrialization, these enterprises should enjoy abundant resources of capital, technology and market, and have the capacity to produce high-technology products and bring top services to the market.

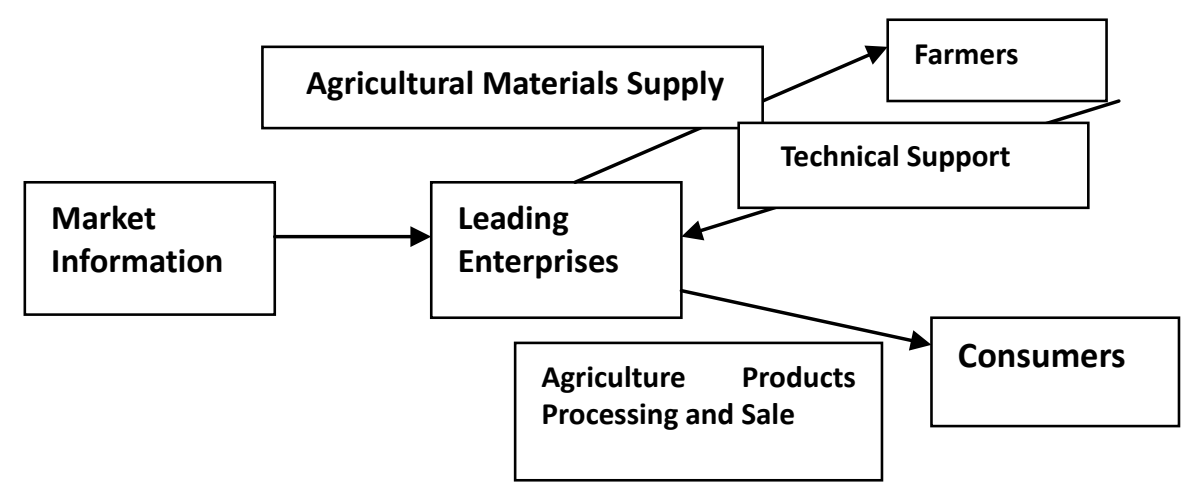

Chart 1. Driven forces of leading enterprises

\subsection{Driven forces of specialized market}

The mode of making use of the driven forces of specialized market follows the trend of specialization and centralization of agricultural industrialization operations. It is a direct and effective organizational model linking farmers and the market, consisting of two organizational patterns: specialized market + farmer households, and specialized market + transportation and sale organization + farmers. Based on local advantages, the specialized market driving mode expands commodity distribution channels through the development of various types of agricultural products markets, especially specialized agricultural product wholesale markets. Under the guidance of market mechanism and demands, it promotes industrialized production of agriculture in certain areas. Through this, a coordinated process of production, processing and sales can be established. In practice, this mode is represented by production base wholesale market, consumption base wholesale market and innovative consumption base supermarkets. However, this mode usually faces difficulties in financing, thus requiring more support from government. The main task of this mode is to provide market information services, including agricultural capital information, production technology information and product sales information. Enjoying advantages in price discovery, specialized market is the center of information exchange and price formation and 
generates large demands. Due to these features, the specialized market is enabled to make a stable and invisible agreement with neighboring farmers and product transportation and sale organizations, thus promoting regional specialized production.

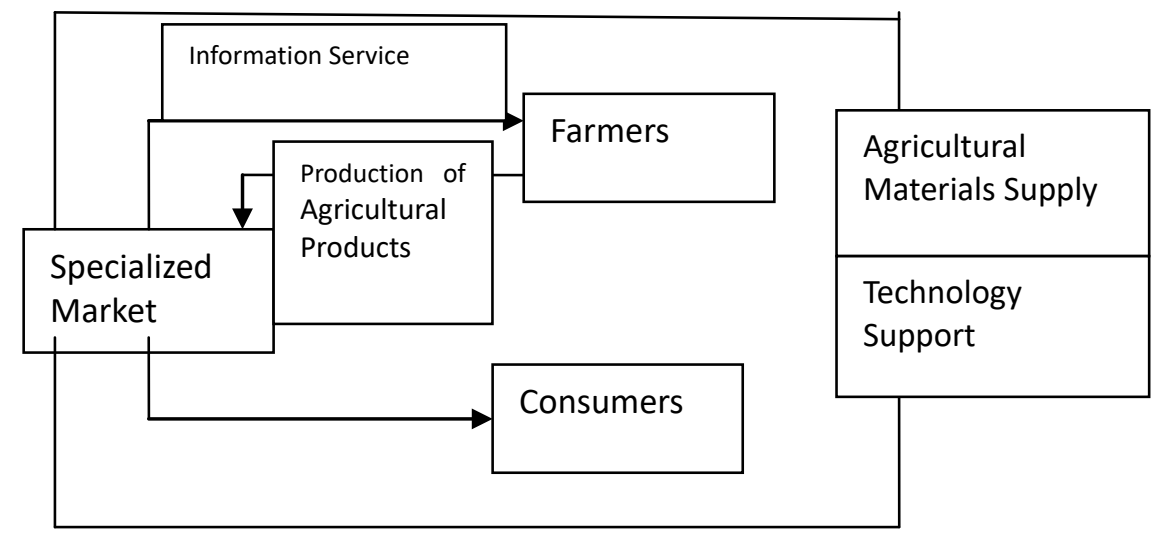

Chart 2. Driven forces of specialized market

\subsection{Driven forces of intermediary organizations}

In the mode of developing driven forces of intermediary organizations, professional cooperative economic organizations and cooperatives work as intermediary agents. Based on cooperative mechanisms or shareholding co-operative system and other interest-linking mechanisms, farmers are motivated to engage in scientific professional production and management. By doing that, an integrated operating system combing production, processing, and sales can be established. The intermediary organizations driving mode usually stands out with two patterns: cooperative economic organization + farmers and professional association + farmers. Cooperative economic organizations are often established under the guidance of government departments, leading enterprises, or large-scale professional farmer households. Farmers included in these organizations participate voluntarily, following principals of equality, mutual benefits and sole responsibility for one's own profit or losses. On the basis of farmer household management, it integrates resources of certain industry or product. At the same time, cooperation in capital, technology, production, purchase and sales and processing can be seen to increase the income of members. Apart from increasing economic benefits, it can also improve agricultural production management through practice and experiences.

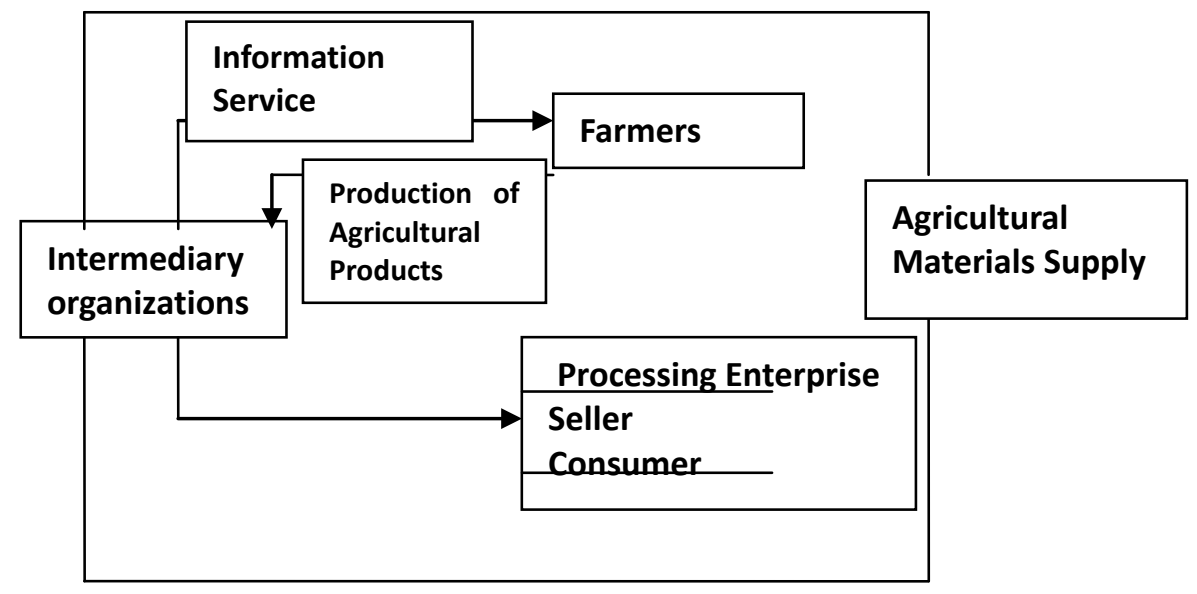

Chart 3. Driven forces of intermediary organizations

\section{Conclusions}

The development of agricultural industrialization is a dynamic process over a long period of time. Currently, there are many factors that restrict the development of China's agricultural 
industrialization. The main problems boil down to market and management failures. Based on the definition and requirements of agricultural industrialization, this paper proposed solutions to existing problems of China's agricultural industrialization: to promote agricultural industrialization on the basis of regional advantages, launch smart and scientific development plans, adhere to market-oriented and benefit-centered development strategy, improve scientific and technological support, increase the driven forces of leading enterprises, and develop multi-pronged agricultural industrialization model. By doing that, China's agricultural industrialization can be promoted from all fronts in the near future.

\section{References}

[1] Disentangling the consensus frame of food security: The case of the EU Common Agricultural Policy reform debate[J]. Jeroen J.L. Candel, Gerard E. Breeman, Sabina J. Stiller, Catrien J.A.M. Termeer. Food Policy. 2014

[2] Land reform and land fragmentation in Central and Eastern Europe[J]. Morten Hartvigsen. Land Use Policy . 2014

[3] Land market liberalization, transfer of agricultural technology, and the process of industrialization[J]. George Vachadze. Land Use Policy . 2013

[4] Farmers' perceptions of safe use of pesticides: determinants and training needs[J]. Seyyed Mahmoud Hashemi, Seyed Mahmood Hosseini, Mohammad Kazem Hashemi. International Archives of Occupational and Environmental Health. 2012 (1)

[5] NEW FARMERS AND NETWORKS: HOW BEGINNING FARMERS BUILD SOCIAL CONNECTIONS IN FRANCE[J]. KATEMAILFERT. Tijdschrift voor economische en sociale geografie. 2007 (1) 